\title{
Design emocional e museu interativo: um passeio pela Casa do Rio Vermelho
}

\author{
Emotional design and interactive museum: a stroll through the Casa do Rio Vermelho
}

MACHADO, Andrea de Matos; Mestre; Universidade Federal da Bahia

andreamachado3d@gmail.com

MARIÑO, Suzi Maria; Doutora; Universidade Federal da Bahia

suzimarino@gmail.com

\section{Resumo}

Este artigo tem por objetivo observar a visitação do público em um museu de interação social, e analisar como o design emocional pode contribuir para a melhoria da experiência do usuário. Para mensurar quais ambientes tem maior influência emocional, foi desenvolvida uma ferramenta específica baseada nos níveis do design emocional (visceral, comportamental e reflexivo) propostos por Norman (2008). A instituição cultural selecionada para o estudo foi a Casa do Rio Vermelho, um museu memorialista que retrata a obra do romancista brasileiro Jorge Amado e seu cotidiano junto à esposa, fotógrafa e também escritora brasileira, Zélia Gattai. Este trabalho é parte da construção de uma tese de Doutorado. Os resultados obtidos, até o momento, reiteram a importância do design emocional como agente facilitador do processamento das informações e compreensão de uso dos espaços, estimulador da memória afetiva e do pensamento criativo, visando auxiliar na organização de acervos de museus e instituições culturais, a partir de estratégias mais assertivas e personalizadas de melhorar a experiência do usuário.

Palavras Chave: design emocional; museu; interatividade.

\begin{abstract}
This article aims to observe the public visitation in a museum of social interaction, and to analyze how the emotional design can contribute to the improvement of the user experience. To measure which environments have the greatest emotional influence, a specific tool was developed based on the levels of emotional design (visceral, behavioral and reflexive) proposed by Norman (2008). The cultural institution selected for the study was Casa do Rio Vermelho, a memorialist museum that portrays the work of Brazilian novelist Jorge Amado and his daily life with his wife, photographer and also a Brazilian writer, Zélia Gattai. This work is part of the construction of a doctoral thesis. The results obtained, so far, reiterate the importance of emotional design as an agent that facilitates information processing and comprehension of space use, as a stimulator of affective memory and creative thinking, aiming to assist in the organization of museum collections and cultural institutions, from more assertive and personalized strategies to improve the user experience.
\end{abstract}

Keywords: emotional design; museum; interactivity. 


\section{Interatividade em museus}

Uma das premissas no ofício da museologia é a preservação e salvaguarda do acervo, o que corrobora para que museus e instituições culturais disponibilizem as informações ao visitante tradicionalmente por meio de observação contemplativa, visual e passiva. Em contrapartida, é notório observar que a interatividade ${ }^{1}$ em museus está em plena ascensão, sobretudo em museus contemporâneos. Para Muchacho (2005, p. 1540), "a instituição museológica sofreu grandes alterações [...] havendo, agora, consciência de que necessita se libertar do seu espaço tradicional e limitado, para se tornar acessível ao grande público".

A crescente utilização de mecanismos e recursos de estimulação sensorial, sejam eles físicos ou virtuais, tornam-se alternativas para facilitar a compreensão da própria obra e do contexto histórico de sua produção, "com o objetivo de intervir no modo como as pessoas assimilam as ideias, ou se relacionam com os objetos de uma exposição, tornando supostamente mais fácil, divertida e interessante a absorção do conteúdo ou a visita a um museu". Vale ressaltar que as Tecnologias de Informação e Comunicação - TICs estão cada vez mais ubíquas, isto é, onipresentes e globalmente difundidas no cotidiano, conectando pessoas, lugares e objetos. Contudo, é importante advertir que "o uso recorrente e irrefletido das novas tecnologias nas salas de exposição tem levado a uma sacralização equivocada dos dispositivos digitais como alternativas únicas e infalíveis para a instauração da interatividade e do prazer na experiência museal" (Oliveira et al, 2014, p. 22).

De acordo com Wagensberg (2006), a interatividade, tendo o visitante como um elemento ativo na exposição, pode ser categorizada em três modalidades: "hands on", "minds on" e "heart on", ilustradas no Quadro 1.

Quadro 1 - Dimensões da interatividade segundo Wagensberg, 2006.

\begin{tabular}{ll}
\hline Modalidades de interatividade & Descrição sucinta \\
\hline $\begin{array}{l}\text { 1. HANDS ON ou } \\
\text { Interatividade "mão na massa" }\end{array}$ & $\begin{array}{l}\text { O visitante é estimulado a manipular objetos e/ou } \\
\text { peças da exposição para obtenção de respostas } \\
\text { ou acessar informações por meio de acionamento } \\
\text { tátil. }\end{array}$ \\
\hline $\begin{array}{l}\text { 2. MINDS ON ou } \\
\text { Interatividade mental }\end{array}$ & $\begin{array}{l}\text { Os recursos empregados destinam-se a estimular } \\
\text { o raciocínio e a reflexão, para que o visitante } \\
\text { possa responder ou ponderar questões, criando- } \\
\text { se uma expectativa competitiva com ele mesmo e } \\
\text { incentivando também o pensamento consciente. }\end{array}$ \\
\hline $\begin{array}{l}\text { 3. HEART ON ou } \\
\text { Interatividade emocional }\end{array}$ & $\begin{array}{l}\text { O visitante cria identidade e estabelece vínculos } \\
\text { com a exposição, os objetos ou peças, } \\
\text { despertando a memória afetiva. }\end{array}$ \\
\hline
\end{tabular}

Fonte: própria (2018)

Dinis (2010) reforça que fomentar a interatividade é uma oportunidade de conquistar o público-alvo e agregar valor ao produto através da diferenciação. Assim, a ação interativa entre o

\footnotetext{
${ }^{1}$ Neste estudo, a interatividade foi considerada como a troca de ações centradas no usuário, seja ela interventiva ou participativa, na relação entre homem-máquina-ambiente.
} 
visitante e o acervo, estabelece uma relação pessoal e emocional associada à cognição e permite ampliar sua capacidade de percepção.

As pesquisas de Norman (2008) estão relacionadas à esfera emocional do design e, portanto, quando aplicadas assertivamente, tornam-se uma fonte de promoção de emoções geradoras de prazer e bem-estar. Neste sentido, diretrizes projetuais conduzidas pelo design emocional ${ }^{2}$ colaboram para melhoria da experiência do usuário, uma vez que a comunicação com o público se torna um desafio incessante para o museu, e que vem ao longo do tempo, modificando o projeto ou organização expográfica, de maneira a valorizar a interação social.

\section{Design emocional - a teoria de Norman}

O termo 'design emocional' foi difundido internacionalmente a partir da década de 1980, conhecido como uma vertente do design que objetiva considerar na atividade projetual, os fatores emocionais dos usuários, com a intenção de desencadear experiências agradáveis, a partir da relação destes com produtos e serviços. Nesta perspectiva, o cientista cognitivo Donald Norman, PhD em Psicologia e professor de ciência da computação e psicologia na Northwestern University, apresenta-se como um dos precursores desta área. Norman $(2008$, p.13) defende que "as emoções são inseparáveis da cognição e fazem parte de um sistema de julgamento do que é bom ou ruim, seguro ou perigoso e de formulação de juízos de valor que nos permitem sobreviver melhor. Elas são guias constantes em nossas vidas, afetando a maneira como nos comportamos, pensamos, tomamos de cisões e interagimos uns com os outros". De acordo com o autor, um projeto de design, com foco nas questões emocionais, apresenta três esferas interligadas: visceral, comportamental e reflexiva, caracterizadas nas subseções posteriores, e ainda ratifica que não há design sem todas as três.

“[...] design emocional, ao contrário do que o nome pode sugerir, é uma das áreas do design mais facilmente caracterizáveis como científicas, na medida em que trabalha com teoria, método e resultados de pesquisa que permitem a elaboração de afirmações sobre a experiência" (TONETTO, 2011 p.133).

\subsection{Esfera visceral do design emocional}

Refere-se aos aspectos físicos, que suscitam reações instintivas do ser humano, relativo à estrutura cerebral pré-consciente, isto é, que antecede o pensamento, nível subconsciente, a "primeira impressão". São os aspectos influenciados pela aparência, caracterizados por julgamentos rápidos, que estimulam de maneira primitiva os sentidos: importância para sensação física, texturas dos materiais, cheiros, sons, "relacionados à percepção direta" (Norman, 2008; Tonetto, 2011).

\subsection{Esfera comportamental do design emocional}

Neste nível de processamento de informações, a ênfase está na experiência com o produto, na facilidade e compreensão de uso, relativo a desempenho, funcionalidade, usabilidade. São as respostas aprendidas, mas automáticas e inconscientes por parte do usuário. As coisas que importam neste nível são os quatro componentes do bom design comportamental: função,

\footnotetext{
${ }^{2}$ Vertente do Design que se baseia na atividade projetual a partir do estabelecimento de conexões emocionais entre usuário-produto-ambiente.
} 
compreensibilidade, usabilidade e a sensação física. Satisfazer necessidades. "O primeiro passo do bom design comportamental é compreender exatamente como as pessoas vão usar um produto" (Norman, 2008, p. 93; Tonetto, 2011).

\subsection{Esfera reflexiva do design emocional}

Depois da função vem a compreensão, a razão, a lógica, o sentido. Na alçada reflexiva do design emocional, interpretação, raciocínio e consciência são os fatores dominantes e concentramse essencialmente na parte contemplativa do cérebro, na autoimagem e memória. Estão relacionados às experiências pessoais, crenças, culturas e identidades dos usuários (Norman, 2008; Tonetto, 2011).

"[...] designers profissionais podem criar produtos que sejam um prazer de olhar e usar. Mas não podem tornar alguma coisa pessoal ou com a qual se criem vínculos. "Ninguém pode fazer isso por nós: temos de fazê-lo nós mesmos" (Norman, 2008, p.18).

O museu memorialista A Casa do Rio Vermelho foi selecionado como objeto de estudo para observar a experiência do usuário, e assim, analisar a correlação emocional e significativa entre homem-objeto-ambiente, a partir da organização do acervo e distribuição do projeto expográfico 3 definido.

\section{A Casa do Rio Vermelho}

Situada na Rua Alagoinhas, no 33, Rio Vermelho, bairro boêmio da capital baiana, foi por anos a moradia de Jorge Amado, importante romancista brasileiro e sua esposa Zélia Gattai, também escritora, além de fotógrafa e memorialista. Ambos imortais da Academia Brasileira de Letras. O imóvel foi adquirido por intermédio da venda dos direitos do livro "Gabriela, Cravo e Canela", uma das mais conhecidas obras do escritor (GATTAI, 1999). O lugar se tornou ponto de encontro de amigos, intelectuais e políticos em uma área de aproximadamente dois mil metros quadrados. Atualmente, a casa foi transformada em uma instituição museológica, cuja composição expográfica apresenta espaços de interatividade, onde o visitante pode ambientar-se ao cotidiano da época e acessar as informações de uma maneira seletiva e sensorial sobre a vida, construção literária e produção artística dos escritores.

\subsection{Os ambientes da casa e os recursos expográficos}

Após identificar-se na recepção do pavimento térreo, o visitante dirige-se ao pavimento superior para explorar os ambientes da Casa do Rio Vermelho. Não há uma trajetória determinada, o usuário pode escolher o seu percurso, exceto pelas duas visitas guiadas, que acontecem diariamente durante o período de funcionamento, e que neste caso, são conduzidas pelos mediadores do museu. Neste momento, o visitante pode escolher participar do grupo ou continuar seu roteiro individual.

O acervo foi organizado de maneira a inserir o visitante como um amigo, e propicia vivenciar os ambientes de maneira acolhedora, emocional, sensorial e interativa. A maioria dos espaços foi

\footnotetext{
${ }^{3}$ Conjunto de técnicas para o desenvolvimento de uma exposição constituído basicamente pela articulação entre o conteúdo, a ideia e a forma.
} 
equipada com dispositivos audiovisuais de transmissão programada, mas também, apresenta ambientes cujo acionamento se dá por seleção, intervenção ou coparticipação do próprio visitante, como apontado nas pesquisas de Wagensberg (2006).

Para desdobramento desta pesquisa foram selecionados 13 ambientes que abarcam a obra, a produção artística, as memórias afetivas e a rotina social vivida pelos dois escritores. Os locais e mecanismos de interação e estimulação sensorial utilizados foram descritos no Quadro 2.

Quadro 2 - Ambientes da casa e recursos expográficos relacionados.

\section{Descrição dos ambientes}

\section{A BAHIA DE JORGE AMADO}

Conhecido como a "sala de visita", é um dos primeiros ambientes apresentados durante as mediações. Todo o mobiliário é original, pode-se encontrar a máquina de datilografia que o escritor costumava escrever suas obras, além de coleções (discos, livros, esculturas) de artistas internacionalmente conhecidos. O ambiente é sonorizado pela música do cantor e compositor baiano, Dorival Caymmi.

\section{A AMIZADE É O SAL DA VIDA}

Ou o "quarto de hóspedes", apresenta objetos de época, vestimentas características e preferenciais do escritor. Exibe narrações da relação fraterna com os amigos que se hospedaram na casa, dentre eles: Dorival Caymmi Glauber Rocha, Jack Nicholson, Pablo Neruda, Paul Sartre, Roman Polanski, Simone de Beauvoir e Tom Jobim.

\section{Descrição dos recursos expográficos}

1.1 Dispositivo audiovisual, acionamento programado;

1.2 Objetos, telas, esculturas, mobiliário de época.

\section{AMORES E AMANTES}

O "quarto do casal" exibe projeções nas paredes de imagens relacionados aos romances dos personagens retratados na obra do escritor e na cama do casal, exibições referenciadas de narrativas românticas presentes nos livros de Jorge Amado.
2.1 Projeções audiovisuais nas paredes de acionamento programado;

2.2 Vestimentas típicas do escritor.

\section{ZÉLIA GATTAI, COMPANHEIRA GRAÇAS A DEUS}

$\mathrm{O}$ ambiente é dedicado à arte de Zélia Gattai. É o lugar onde está alocado seu laboratório de fotografia. Exibe uma árvore genealógica representada por bonecos que mescla costura com retratos dos entes familiares. Apresenta também uma cabine audiovisual que narra a história da família Gattai.

\section{TROCANDO CARTAS / O COMUNISTA}

O ambiente representa "o closet" e traz registros do casal durante a época da ditadura no Brasil, como militantes comunistas. Neste espaço, o visitante pode visualizar objetos pessoais e peças das viagens do casal de escritores, e também, acessar os compartimentos para leitura dos documentos intercambiados com amigos como Carlos Drummond de Andrade, Oscar Niemeyer,
3.1 Dispositivo audiovisual de acionamento programado;

3.2 Objetos pessoais, peças e esculturas dos escritores. 
Yoko Ono, Oscar Niemeyer, Monteiro Lobato.

\section{OS AMADOS SABORES DE JORGE}

Conhecido como "a primeira cozinha", o ambiente original foi preservado. Exibe, além dos artefatos e utensílios do cotidiano de época do casal de escritores, uma coleção de poemas inscritos em pratos de cerâmica pelo músico e compositor Tom Zé. Há também, a azulejaria do artista plástico Carybé, composições em cacos de cerâmica por Udo Knoff e sugestões arquitetônicas de Lina Bo Bardi.

\section{A COZINHA DE DONA FLOR}

Ambiente cenográfico, destaca-se pela estimulação sensorial, visual, tátil, auditiva e olfativa. Neste espaço, pode-se tocar, sentir o cheiro e experimentar os temperos da culinária baiana, muitos deles fizeram parte da culinária que permeava a obra do escritor em personagens memoráveis de seus romances como Gabriela e Dona Flor. É também possível que o usuário interaja com o espaço, selecionando receitas típicas, permitindo visualizar a feitura do prato no ambiente através de equipamento audiovisual sensível ao toque, e também, podendo enviar por correio eletrônico.

\section{SALA DE LEITURA}

Ambientada com uma sala de cinema rudimentar, podese assistir personalidades, artistas e intelectuais fazendo a leitura de trechos das obras de Jorge Amado.

\section{MUITAS VIDAS, TANTAS OBRAS}

Neste espaço estão reunidas as publicações de Jorge Amado e Zélia Gattai, em mais de quarenta traduções. É um ambiente em que se pode apreciar as xilogravuras que ilustram os cordéis que representam a obra do escritor, onde o visitante pode interagir, selecionar obras para serem cantadas em cordel pelo músico, repentista, escritor e poeta brasileiro Bule-Bule.

10. LAGOS DOS SAPOS, O GATO MALHADO E A ANDORINHA SINHÁ

Antiga piscina da casa, foi transformada em um lago artificial que faz alusão à paixão do escritor por sapos.

\section{VARANDA FECHADA}

Em formato de " $L$ ", apresenta vitrines que preservam objetos das coleções do escritor. Pode-se encontrar peças e esculturas de artistas populares locais e também internacionalmente conhecidos: Di Cavalcanti, Miró, Picasso, entre outros. Os acessos a este espaço são resguardados por gradis do artista plástico Mário Cravo.

\section{RODA DE CONVERSA SOBRE JORGE AMADO}

Quiosque que exibe diversas personalidades relatando suas impressões pessoais sobre Jorge Amado.
6.1 Dispositivo audiovisual de acionamento programado;

6.2 Artefatos de coleções, móveis e utensílios de época.

7.1 Equipamento audiovisual acionado pelo visitante via dispositivo de acionamento tátil: permite a seleção da informação e encaminhamento das informações via correio eletrônico;

7.2 Estimulação tátil, olfativa e palatável por meio de matérias-primas (temperos) utilizadas e referenciadas na obra e culinária pessoal do escritor.

8.1 Projeção audiovisual em parede de acionamento programado;

9.1 Equipamento audiovisual de acionamento programado;

9.2 Dispositivo audiovisual com seleção de obra, acionamento das informações e controle de volume feito pelo visitante.

9.3 Xilogravuras que versa a obra do escritor.

10.1 Dispositivo auditivo de acionamento programado que reproduz o som dos animais.

11.1 Dispositivo auditivo de acionamento programado;

11.2 Objetos e esculturas de coleções do escritor. 
13. JORGE E O CANDOMBLÉ

Quiosque equipado com dispositivo audiovisual que exibe a trajetória e a relação de Jorge Amado com sua religião de matriz africana, o candomblé.
13.1 Equipamento audiovisual acionado pelo visitante;

13.2 Elementos cunhados em metal que remetem à cultura candomblecista de representação dos orixás;

13.3 Instrumentos musicais.

Fonte: própria (2018)

\section{Aspectos metodológicos}

A partir de uma abordagem heurística, foi planejada pesquisa etnográfica para observação da experiência do público visitante do museu, e elaboração do mapeamento das dimensões emocionais do design na exposição, baseadas na teoria proposta por Norman (2008).

O procedimento metodológico adotado implicou na criação e aplicação de uma ferramenta infográfica, detalhada em 4.1, como instrumento de coleta e tabulação dos dados, para verificar se a organização do acervo associada à estimulação sensorial, recursos interativos e conexão emocional: a) auxilia na mensuração dos níveis do design emocional; b) influencia na experiência e satisfação do visitante de maneira significativa e c) promove uma melhor experiência quanto ao processamento das informações, percepção do ambiente e memória afetiva agradável.

\subsection{Ferramenta de mapeamento do design emocional a partir da observação da experiência do usuário}

A ferramenta, ilustrada na figura 1, foi subdividida em quatro campos. O primeiro campo tem por objetivo identificar o perfil do público quanto à cidade de origem, profissão, faixa etária e gênero. $O$ campo assinalado pelo número 2 , lista os ambientes visitados e aponta um ícone (coração inscrito em um círculo) para que o visitante indique o ambiente de sua preferência. $O$ terceiro campo apresenta uma escala de satisfação emocional por intermédio de configuração iconográfica de expressão facial que varia do "gostei muito" ao "detestei". O campo 4 faz referência às dimensões do design emocional e apresenta ícones como descritos na figura 2 que indicam respectivamente o nível de percepção direta do ambiente vinculado ao campo visceral com a interrogativa "desperta atenção? "; o nível de processamento operacional e entendimento do uso do ambiente ("fácil de usar?"). E por fim, a esfera reflexiva, para mensurar a estimulação da memória afetiva do visitante - "lembra algo?". 
Figura 1 - Ferramenta de mapeamento dos níveis de design emocional e experiência do usuário

\begin{tabular}{|c|c|c|c|c|c|c|c|c|c|}
\hline \multicolumn{10}{|c|}{ AVALIAÇĀO DA EXPE 1 VCIA EM MUSEU - “A CASA DO RIO VERMELHO” } \\
\hline Cida & e (opcional)___ & & & & & & despertou atençăo? & fácil de usar? & lembra algo? \\
\hline$(0)$ & $\begin{array}{ll}\text { ammarque o os } \\
\text { amblente tavorito }\end{array}$ AMBIENTES VISITADOS & 항 & $(-)$ & $(\bullet)$ & (8) & (8) & (1) & & 4 \\
\hline & A BAHIA DE JORGE AMADO (A SALA) & & & & & & $\begin{array}{l}\text { ISlm, fortemente } \\
1 \text { Sim, um pouco } \\
\text { INāo, neutro } \\
\end{array}$ & $\begin{array}{l}\text { (1) Sim } \\
\text { () Nào } \\
\text { () Nâo usei }\end{array}$ & $\begin{array}{l}\text { (1) Sim, algo positivo } \\
\text { (1) Sim, algo negativo } \\
\text { ( ) Nä lembra tha }\end{array}$ \\
\hline & A AMIZADE É O SAL DA VIDA (O QUARTO DE HÓSPEDES) & & & & & & \begin{tabular}{|l} 
ISim, fortemente \\
1 Sim, um pouco \\
inào, neutro \\
\end{tabular} & $\begin{array}{l}\text { () Sim } \\
\text { (1) Não } \\
\text { () Não usei }\end{array}$ & $\begin{array}{l}\text { (1) Sim, algo positivo } \\
\text { () Sim, algo negativo } \\
\text { () Nä lembra }\end{array}$ \\
\hline & AMORES E AMANTES (O QUARTO DE JORGE E ZÉLIA) & & & & & & \begin{tabular}{|l|} 
|Sim, fortemente \\
1 Sim, um pouco \\
INăo, neutro \\
\end{tabular} & 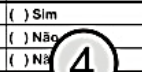 & $\begin{array}{l}\text { () Sim, algo positivo } \\
\text { (1) Sim, algo negativo } \\
\text { () Năo lembra }\end{array}$ \\
\hline & ZÉLIA GATTAI, COMPANHEIRA GRAÇAS A DEUS (A ARTE DE ZÉLIA) & & & & & & \begin{tabular}{|l|} 
|S Sim, fortemente \\
ISim, um poucco \\
INăo, neutro \\
\end{tabular} & $\begin{array}{l}\text { (1) sinh } \\
\text { (1) Năo } \\
\text { (1) Nâousei }\end{array}$ & $\begin{array}{l}\text { () Sim, algo positivo } \\
\text { (1) Sim, algo negativo } \\
\text { (1) Nâolembra }\end{array}$ \\
\hline & TROCANDO CARTAS I O COMUINISTA (O CLOSET) & & & & & & \begin{tabular}{|l|} 
|Sim, fortemente \\
1 Sim, um pouco \\
INāo, neutro \\
\end{tabular} & $\begin{array}{l}\text { () Sim } \\
\text { ( ) Não } \\
\text { ( ) Não usei }\end{array}$ & $\begin{array}{l}\text { () Sim, algo positivo } \\
\text { (1) Sim, algo negativo } \\
\text { (1) Nãol lembra }\end{array}$ \\
\hline & OS AMADOS SABORES DE JORGE (A PRIMEIRA COZINHA) & & & & & & \begin{tabular}{|l|} 
1Sim, fortemente \\
1 Sim, um pouco \\
INăo, neutro \\
\end{tabular} & $\begin{array}{l}\text { (1) Sim } \\
\text { (1) Nāo } \\
\text { (1) Năo usei }\end{array}$ & $\begin{array}{l}\text { () Sim, algo positivo } \\
\text { () Sim, algo negativo } \\
\text { () Năo lembra }\end{array}$ \\
\hline & A COZINHA DE DONA FL (2) CEITAS TIPICAS) & & & & & & \begin{tabular}{|l|} 
Isim, fortemente \\
ISim, um pouco \\
INâo, neutro \\
\end{tabular} & $\begin{array}{l}\text { () Sim } \\
\text { (1) Não } \\
\text { ( ) Nâousei }\end{array}$ & $\begin{array}{l}\text { () Sim algo positivo } \\
\text { 1) Sim, algo negativo } \\
\text { (1) Nâ lembra }\end{array}$ \\
\hline & SALA DE LEITURA (A SALA DE CINEMA) & & & & & & \begin{tabular}{|l|} 
Isim, fortemente \\
Isim, um pouco \\
INăo, neutro \\
\end{tabular} & $\begin{array}{l}\text { ( ) Sim } \\
\text { ( ) Não } \\
\text { ( ) Nâo usei }\end{array}$ & $\begin{array}{l}\text { (1) Sim, algo ossitivo } \\
\text { (1) Sim, algo negativo } \\
\text { ( ) Nâo lembra }\end{array}$ \\
\hline & MUITA VIDA, TANTAS OBRAS (A BIBLIOTECA) & & & & & & \begin{tabular}{|l|} 
ISim, fortemente \\
ISim, um pouco \\
INăo, neutro \\
\end{tabular} & $\begin{array}{l}\text { (1) Sim } \\
\text { (1) Não } \\
\text { ( ) Nâo usei }\end{array}$ & $\begin{array}{l}\text { (1) Sim, algo positivo } \\
\text { () Sim, algo negativo } \\
\text { (1) Nâo lembra }\end{array}$ \\
\hline & LAGO DOS SAPOS (SOM DOS ANIMAIS) & & & & & & \begin{tabular}{|l|} 
|Sim, fortemente \\
ISim, pumpouco \\
INăo, neutro \\
\end{tabular} & \begin{tabular}{|l|} 
() Sim \\
( Năo \\
( ) Nâo usei
\end{tabular} & $\begin{array}{l}\text { () Sim, algo positivo } \\
\text { 1) Sim, alog negative } \\
\text { ( ) Nä lembra }\end{array}$ \\
\hline & VARANDA FECHADA (LIVROS, COLEÇŌES E OBJETOS DO MUNDO) & & & & & & \begin{tabular}{|l|} 
|Sim, fortemente \\
1 Sim, um pouco \\
INăo, neutro \\
\end{tabular} & $\begin{array}{l}\text { () Silm } \\
\text { ( ) Não } \\
\text { ( ) Não usei }\end{array}$ & $\begin{array}{l}\text { () Sim, algo positivo } \\
\text { (1) sim, algo negativo } \\
\text { () ) Nà lembra }\end{array}$ \\
\hline & RODA DE CONVERSA SOBRE JORGE AMADO (CABINE 1 NO JARDIM) & & & & & & \begin{tabular}{|l|} 
|Sim, fortemente \\
| Sim, um poucco \\
INăo, neutro \\
\end{tabular} & $\begin{array}{l}\text { () Sim } \\
\text { () Năo } \\
\text { () Nâousei }\end{array}$ & $\begin{array}{l}\text { () Sim, algo positivo } \\
\text { (1) Sim, algo negativo } \\
\text { (1) Nâolembra }\end{array}$ \\
\hline & JORGE E O CANDOMBLÉ (CABINE 2 NO JARDIM) & & & & & & \begin{tabular}{|l|} 
|Sim, fortemente \\
| Sim, um pouco \\
|Näo, neutro \\
\end{tabular} & $\begin{array}{l}\text { () Sim } \\
\text { () Nào } \\
\text { (1) Nâousei }\end{array}$ & $\begin{array}{l}\text { (1) Sim, algo positivo } \\
\text { () Sim, algo negativo } \\
\text { (1) Nâolembra }\end{array}$ \\
\hline
\end{tabular}

Fonte: própria (2018)

Figura 2 - Desdobramento do campo 4 da ferramenta infográfica

\begin{tabular}{|c|c|c|}
\hline $\begin{array}{c}\text { NÍVEL } \\
\text { VISCERAL }\end{array}$ & $\begin{array}{c}\text { NÍVEL } \\
\text { COMPORT. }\end{array}$ & $\begin{array}{c}\text { NÍVEL } \\
\text { REFLEXIVO }\end{array}$ \\
\hline despertou atenção? & fácil de usar? & lembra algo? \\
\hline () Sim, fortemente & () $\mathrm{Sim}$ & ( ) Sim, algo positivo \\
\hline () Sim, um pouco & ( ) Não & ( ) Sim, algo negativo \\
\hline ( ) Não, neutro & ( ) Não usei & ( ) Não lembra \\
\hline
\end{tabular}

Fonte: própria (2018)

\subsection{Resultados}

A aplicação da ferramenta infográfica para avaliar a experiência do público visitante do museu, ocorreu entre os meses de janeiro a março do ano em curso. Participaram da pesquisa 62 visitantes, categorizados entre diferentes nacionalidades, faixas etárias e profissões. Este instrumento específico de coleta de dados auxiliou na identificação dos fatores que influenciaram emocionalmente a experiência do usuário, investigados a partir dos elementos expográficos. Os dados expressos nos gráficos seguintes refletem as estatísticas sobre as experiências emocionais vivenciadas dentro de cada um dos 13 ambientes encontrados na Casa do Rio Vermelho. 
Do ponto de vista das ocupações, os registros mostram um público heterogêneo, descrito no quadro 3.

Quadro 3 - Profissões do público visitante pesquisado.

\begin{tabular}{ll}
\hline Lista de profissões dos visitantes & \\
\hline Advogado & Fisioterapeuta \\
Agente de negócios & Fotógrafo \\
Agente de transporte & Guia turístico \\
Analista & Historiador \\
Aposentado & Jornalista \\
Artesão & Músico \\
Atendente & Pecuarista \\
Balconista & Professor \\
Bancário & Psicólogo \\
Comerciante & Recepcionista \\
Designer & Revisor \\
Economista & Secretário executivo \\
Educador físico & Segurança \\
Empresário & Sociólogo \\
Enfermeiro & Somelier \\
Escritor & Técnico administrativo \\
Estudante & Turismólogo \\
Farmacêutico & \\
\hline
\end{tabular}

Fonte: própria (2018)

Conforme observado no gráfico 1 , relativo à faixa etária, a pesquisa apontou uma classificação variada abrigando desde o público jovem ao idoso. Neste quesito tiveram as maiores participações as faixas etárias situadas de 30 aos 45 anos (21\%), dos 46 aos 60 (18\%) e dos 19 aos 30 (16\%). Ressalta-se que a maior parte foi constituída pelo público de jovens e adultos. Ratifica-se ainda que entre estes, o gênero predominante foi o feminino, o que reforça um traço demográfico geral do país (PESQUISA NACIONAL POR AMOSTRA DE DOMICÍLIOS, 2015).

Gráfico 1 - Classificação do público visitante por faixa etária e gênero

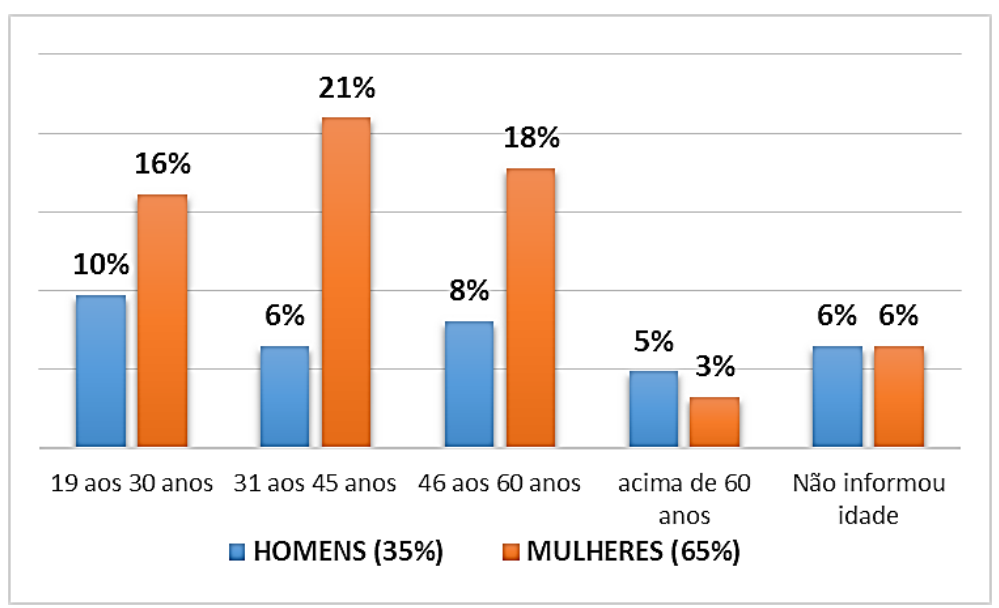

Fonte: própria (2018) 
Considerando o país de origem do público pesquisado, nota-se pelo gráfico 2 que houve participação maciça do Brasil com 90\%. As outras nacionalidades, com menor relevância, abrangeram visitantes de países da América do Sul e Europa; de forma respectiva a Argentina (5\%) e o Uruguai (3\%) e a Bélgica (2\%).

Gráfico 2 - Classificação por nacionalidade do público visitante

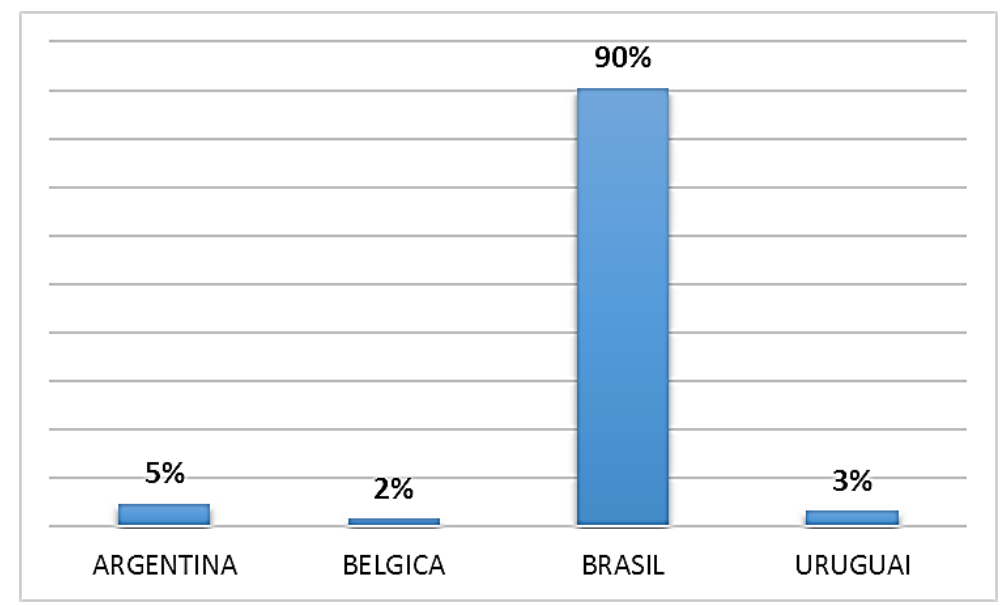

Fonte: própria (2018)

Tendo em vista melhor aprofundar a localidade (estado) de origem do universo pesquisado, constatou-se (gráfico 3) que a maior parte ou $45 \%$ dos respondentes vieram da própria Bahia. Seguidos por São Paulo com 27\%. Nota-se que apesar de menos relevantes em termos percentuais, se observados de forma conjunta, os estados da região Sudeste aqui pesquisados (Minas Gerais, Rio de Janeiro e São Paulo) tem quase a mesma participação da Bahia, ou seja, 41\%.

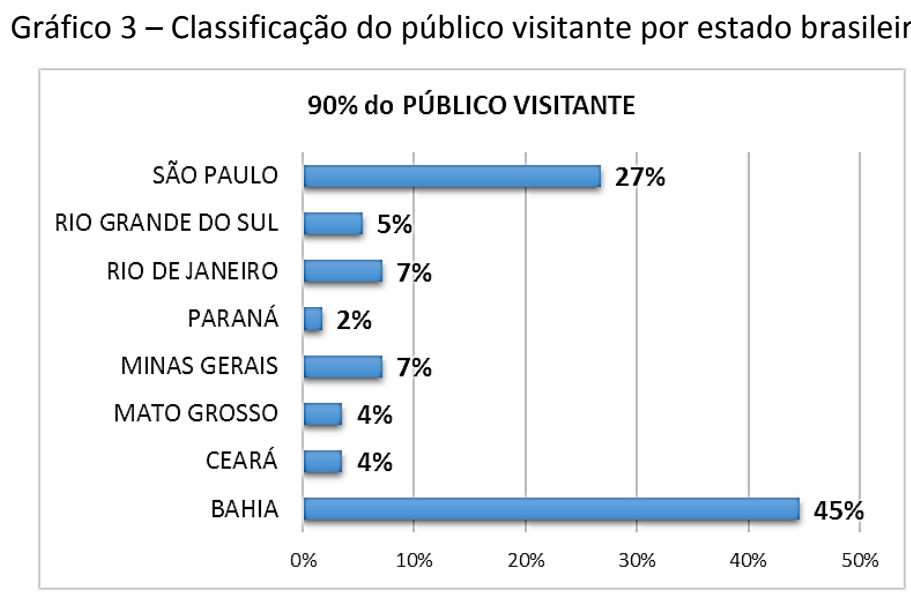

Fonte: própria (2018)

Através do gráfico 4, observa-se que todos os ambientes despertaram a atenção ("sim, fortemente") no nível visceral. Tendo maior destaque "A Bahia de Jorge Amado" com 88\%, seguidos de "Amores e Amantes" $86 \%$ e "Muita vida, tantas obras" com 81\%. Vale reforçar que o caráter de neutralidade ou "Sim, um pouco" foi maior em relação aos espaços "Lagoa dos Sapos" com 13\% e "A amizade é o sal da vida" com $38 \%$. 
Gráfico 4 - Classificação dos ambientes relativa ao nível visceral segundo o público visitante

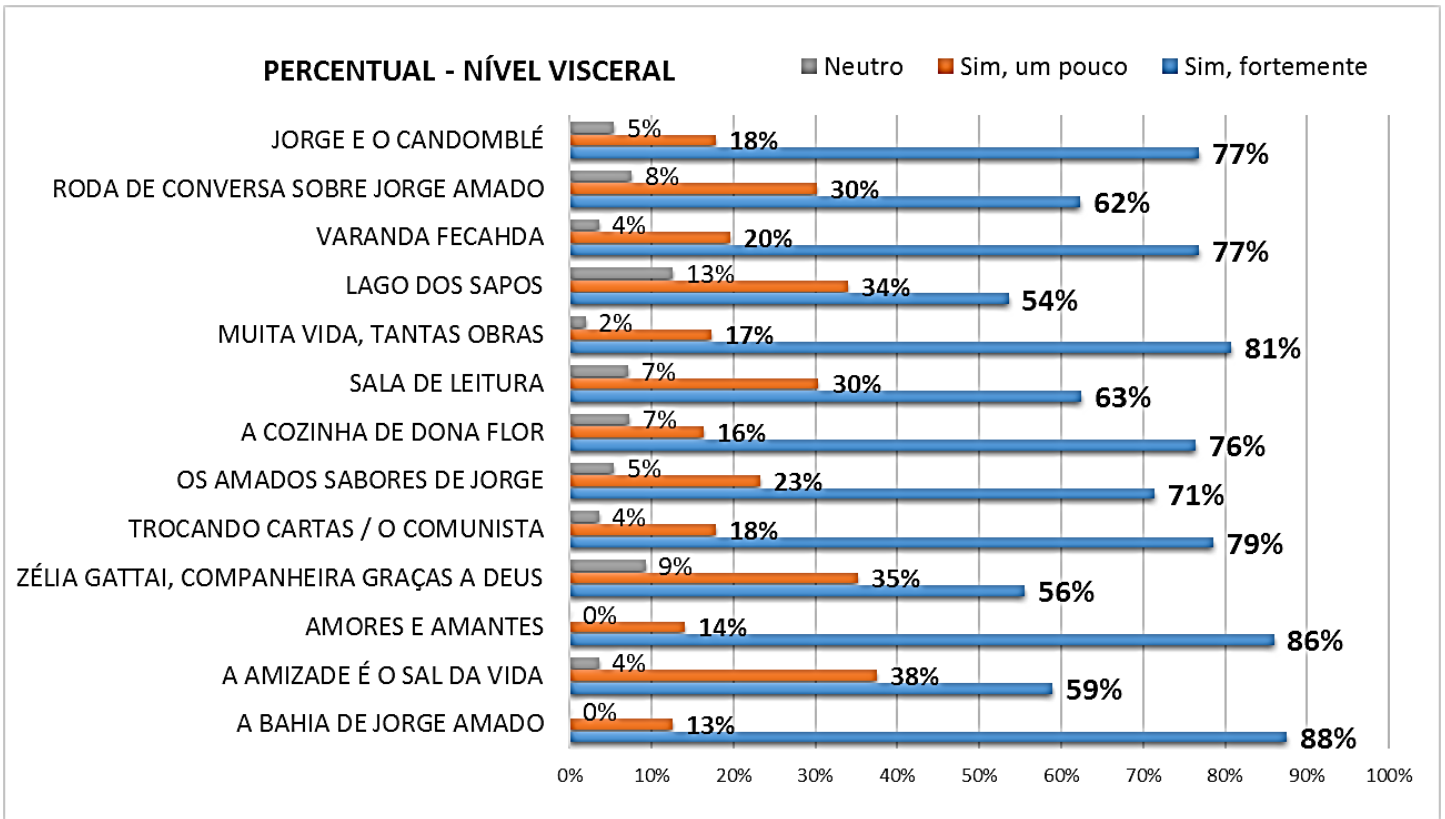

Fonte: própria (2018)

Do mesmo modo, considerando o nível comportamental da experiência, observa-se no gráfico 5, que todos os ambientes visitados foram usufruídos. Chamando a atenção do público o "Trocando cartas" (84\%), "A Bahia de Jorge Amado" (80\%), "A amizade é o sal da vida" com "A cozinha de Dona Flor" e a "Varanda fechada" ambas tiveram 77\% de interesse. Por outro lado, notase que foi alta a falta de uso de alguns ambientes, dentre eles o de menor utilização foi o "Zélia Gatai, companheira graças a Deus" com $43 \%$.

Gráfico 5 - Classificação dos ambientes relativa ao nível comportamental segundo o público visitante

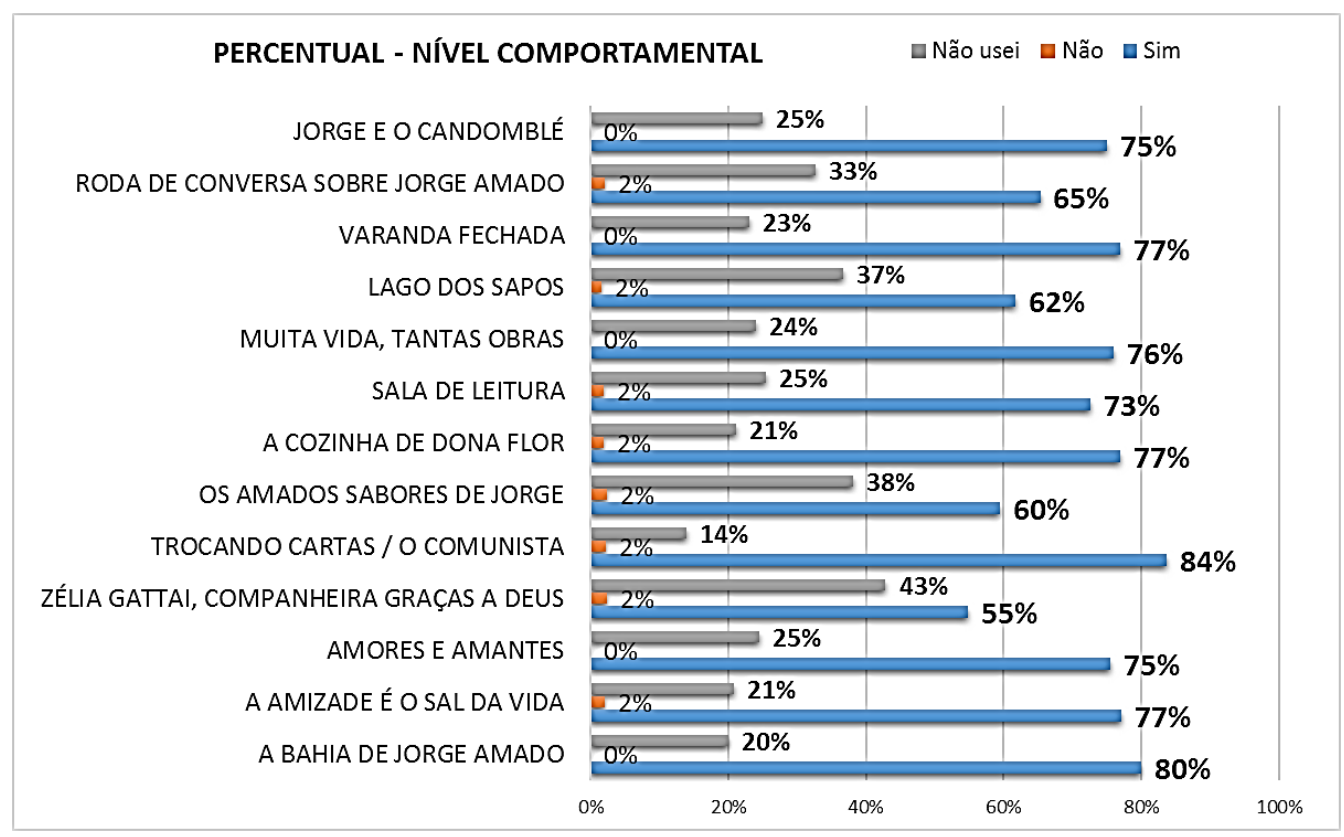

Fonte: própria (2018) 
O nível reflexivo expressado pelo gráfico 6 mostra que a maior parte dos pesquisados relataram uma experiência positiva entre os ambientes visitados. Tais experiências foram sentidas e/ou percebidas de forma mais contundente nos ambientes "A Bahia de Jorge Amado", "Amores e Amantes" e "Varanda Fechada", todos com (94\%). Frisa-se ainda que a sensação de negatividade esteve presente em alguns ambientes, dentre eles com maior, destaque a "Lagoa dos Sapos" (11\%). De outro modo, o sentimento de que não resgatam memória afetivas (item "não lembra"), também relatado foi mais expressivo (17\%) no ambiente "A amizade é o sal da vida".

Gráfico 6 - Classificação dos ambientes relativa ao nível reflexivo segundo o público visitante

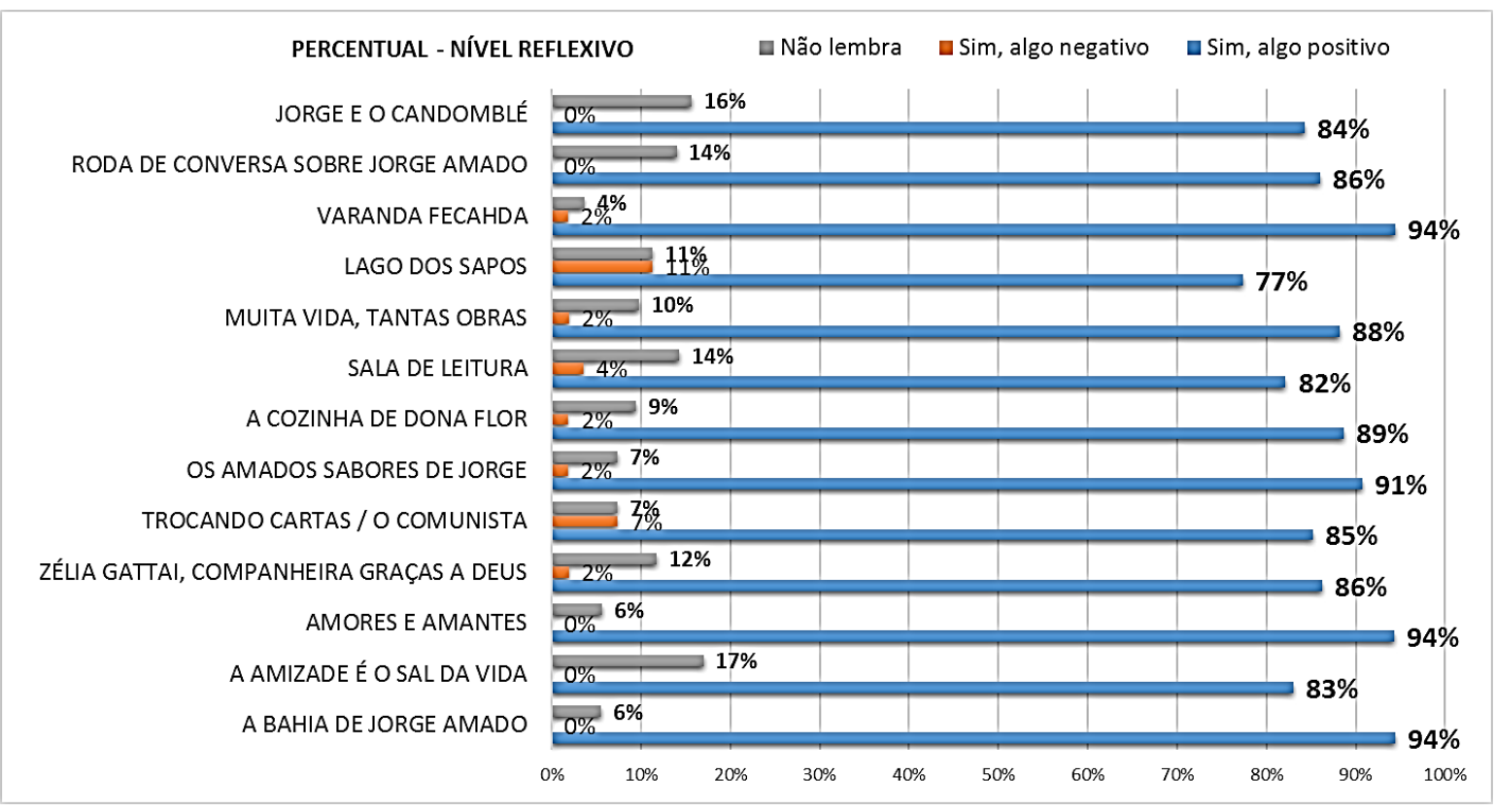

Fonte: própria (2018)

\section{Considerações finais}

Os resultados alcançados demonstraram que, aplicar os fundamentados do design emocional é uma oportunidade de mensurar a conexão afetiva $^{4}$ e a ligação emocional ${ }^{5}$ entre o visitante e a exposição, auxiliar no planejamento e organização do acervo, melhorar a experiência do usuário e favorecer a satisfação do público de museus e instituições culturais. Reforça ainda que, com base na tabulação dos dados, a mediação auxiliada por artefatos e mecanismos sensoriais e/ou interativos facilita a compreensão e o processamento das informações, bem como a percepção do ambiente, e também, estimula a memória afetiva agradável.

A partir das análises dos elementos expográficos dos ambientes da Casa do Rio Vermelho, objeto de estudo em questão, os objetivos que nortearam a pesquisa foram atendidos. A inserção do visitante como um amigo, conduzido por um comportamento de tranquilidade e relaxamento, favorece os processos de raciocínio, imaginação e pensamento criativo. Com base na teoria sobre design emocional proposta por Norman (2008), a investigação mostrou que disponibilizar uma trajetória livre (visitante escolhe por onde seguir) vinculado ao estímulo sensorial, corrobora para o

\footnotetext{
${ }^{4}$ Mudança comportamental inconsciente.

${ }^{5}$ Significados atribuídos a produtos ou ambientes em questão.
} 
desenvolvimento de emoções positivas, facilita o aprendizado, promove o bem-estar e estimula a curiosidade.

Espera-se com esta pesquisa contribuir para expansão dos estudos na área de design emocional, e também, fomentar a criação de ferramentas para correlacionar emoção e cognição, considerando os parâmetros emocionais como instrumentos de comunicação para formular estratégias mais assertivas e personalizadas de planejar o projeto expográfico e mensurar a experiência do usuário. Nessa perspectiva, como trabalhos futuros, sugere-se a realização de outros estudos para identificar parâmetros adequados de organização expográfica, assim como fatores para avaliar a tomada de decisão do público observado, colaborando para entendimento também em outras áreas, e, primordialmente, tendo o design como um gestor estratégico do processo criativo, de planejamento e interpretação das necessidades dos usuários quanto à organização de acervos.

\section{Referências}

DINIS, Patricia M.; SANOTS, Cristiane. Interatividade: homem e objeto de moda. Rio de Janeiro: SENAI/CETIQT, 2010.

GATTAI, Zélia. A casa do Rio Vermelho. Editora Record, 1999.

IBGE TEEN. População: quantidade de homens e mulheres. Disponível em: <https://teen.ibge.gov.br/sobre-o-brasil/populacoa/quantidade-de-homens-e-mulheres.html>. Acesso em: 24 mar. 2018

MUCHACHO, Rute. Museus virtuais: A importância da usabilidade na mediação entre o público e o objecto museológico. SOPCOM: Associação Portuguesa de Ciências da Comunicação, p. 1540-1547, 2005.

NORMAN, Donald A. Design emocional. Rio de Janeiro: Rocco, 2008.

OLIVEIRA, Bernardo Jefferson et al. O fetiche da interatividade em dispositivos museais: eficácia ou frustração na difusão do conhecimento científico. Revista Museologia e património, v. 7, n. 1, p. 21-32, 2014.

TONETTO, Leandro Miletto; DA COSTA, Xavier; CAMPELO, Filipe. Design Emocional: conceitos, abordagens e perspectivas de pesquisa. Strategic Design Research Journal, v. 4, n. 3, 2011.

WAGENSBERG, Jorge. Cosmocaixa. El museo total. Por conversación entre Arquitectos y museólogos. Barcelona: Sacyr, 2006. 